UCRL- 93201

PREPRINT

$$
\begin{aligned}
& \text { Pron by ghi } \\
& \text { SEP O } 21986
\end{aligned}
$$

\title{
TARGET PLANE IMAGING SYSTEM
}

FOR THE NOVA LASER

UCRL--93201

Charles 0 . Swift

Erian S. Bl iss

DE86 015090

W. Al ford Jones

Raymond J. Reeves

Lynn G. Seppala

Randy T. Shel ton

Paul J. VanArsdall

This paper was prepared for submittal to SPIE's 0-E/LASE ' 86

Los Angeles, California

January 19-24, 1986

Cecember 12, 1985

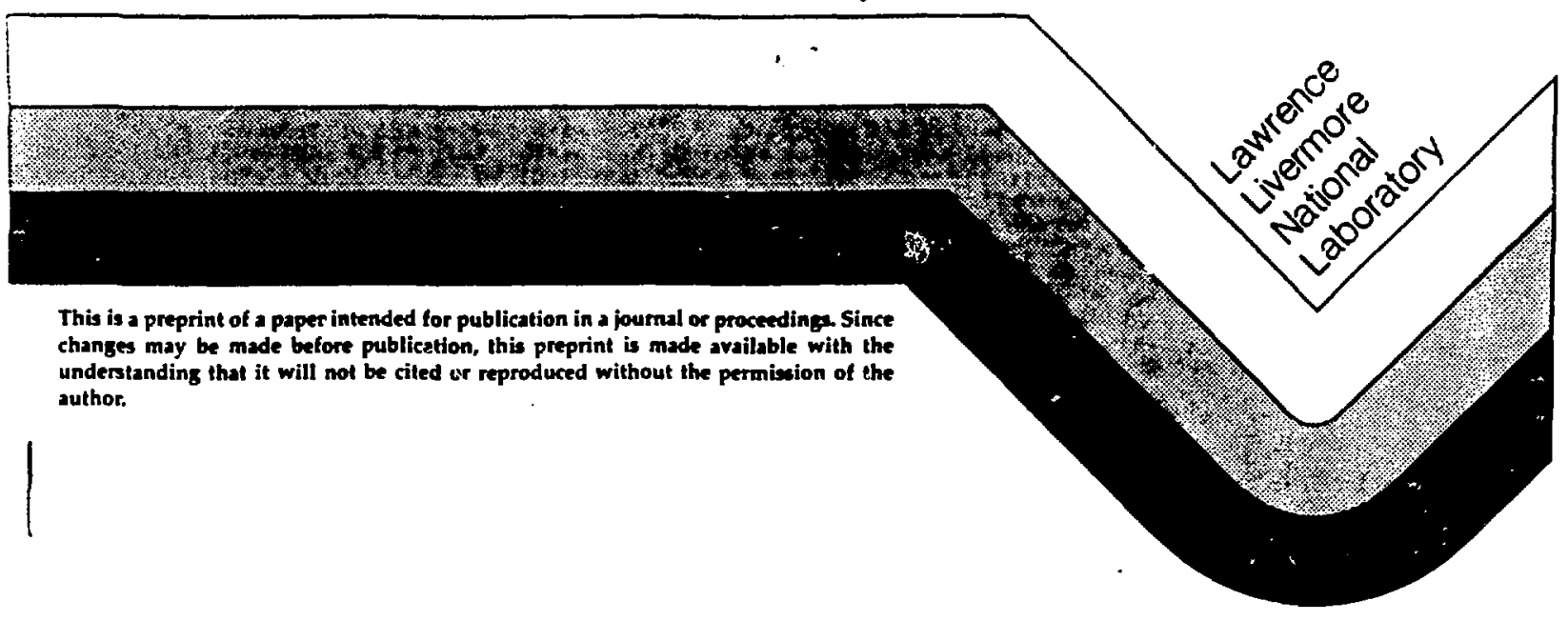


Target plane Imaging system for the Nova laser*

Charles D. Swlft, Erlan S. Bl1ss, W. Alford Jones, Raymond J. Reeves, Lynn G. Seppala, Randy T. She1ton, Paul J. VanArsdali

Lawrence Livermore National Laboratory

P. O. Box 5508, MS L-492, Livermore, Californie 94550

\section{Ahstract}

The Nova Laser, In operation since December 1984, is capable of Irradiating targets with $11 \mathrm{ght}$ at $1.05 \mathrm{\mu m}, 0.53 \mathrm{um}$, and $0.35 \mathrm{us}$. Correct alignment of these harmonic heams uses a system called a target plane lmager (TPI). It is a large nicroscope (four meters long, weighing one thousand $k 1 \log r a m s$ ) that relays Images from the target chamber center to a video optics module located on the outside of the chamber. Several modes of operation are posalble including: near-fleld vfewing and far-fleld viewing at three magnifications and three wavelengths. In addition, the entire fnstrument can he scanned in $X, Y, Z$ to examine various planes near chamber center. Performance of this system and 1to computer controla will be described.

\section{Introduction}

We have been conducting experiments at the Nova laser fac1lity since December, 1984. These experiments require preclse irradiation of amali fuston targets at wavelengths of $1.05 \mathrm{~mm}, 0,53 \mathrm{\mu m}$, and $0.35 \mathrm{wm}$. Performance of the Nova laser has been described elsewhere. $i$ This paper will iescribe the design and operation of a computer controlled target plane lmaging aystem that we use to alfgn the beams to targeta. Figure 1 shows the target plane imager as te is meunter on the Novg target chumber. It is essentlally a large microscope that relays images of the harmonic beams to viewing optics and a video sensor located in a module outalde the chamber vacuum.

\section{Target plane 1mager design}

The system design was driven by the following requirements:

1. Provide remote viewing of focused laser beans at and near chamber center.

2. Provide near-fleld lnages of each full aperture $74 \mathrm{~cm}$ beam.

3. Perform this imaging ac each of the three wavelengths.

4. Have sufficiers sensitivity to form video images when viewing low intensity sources.

Figure 2 is an assembly drawing of the opto-mechanical subsystem that was resigned to satisfy these requirements. There are two major portions to the assembly. There is the optical periscope that forms the images and relays them out of the chamber. It conststs of an $\mathrm{f} / 3$ objective (ejght elements), a one-to-one relay optic (four elenents), and two fleld lenses. The second part to the viewing module that provides viewing caparility at three magnifications of both the neaz-fleld and far-fleld images. These optical essemblies are mounted on $\mathrm{an} X$, $Y$ ranslation stage in orier that a plane $50 \mathrm{~mm} X 50 \mathrm{~mm}$ at chamber center can be examined. In addition, ali the optics (and the video camera) can be ecanned in the $z$ direction to focus on any plane within +25 man of chamber center. Flgure 1 deplets one of the laser heams reflected from the viewIng mirror into the optical periscope. This is the operating mode used when forming near-fleld inages of the beams. Each of the beams can be viewed by tipping the viewing mirror and rotating the periscope to the correct angles in order that the beam of Interest 18 viewed directly. Optics in the viewing module al low examination of the beam at a plane fust outalde the chamber. This $1 \mathrm{~g}$ where the $74 \mathrm{cr}$ target focus leng $1 \mathrm{~s}$ located as well as the RDP crystal array. Therefore, bean alignment to these and other elements of the system can be determined. In order to view far-fleld Images, the viewing mirror is tipped out of the way and Inages of the beams focused on frosted reference targets are viewed directly. This is the most common operating mode.

\section{First order design}

The internal diameter, $D$, of the periscope assembly and 1ta overall length of $3000 \mathrm{~mm}$ constrain the first order design parameters. Given an object $10 \mathrm{~mm}$ In diameter and a front obfective magnification, $M_{1}$, the maximum dianeter of the first internal image is equal to the tube diameter.

\#Work performed under the ausplces of the $U$. S. Department of Energy by the Lawrence Livermore National Laboratory under contract number $W-7405-E N G-48$. 


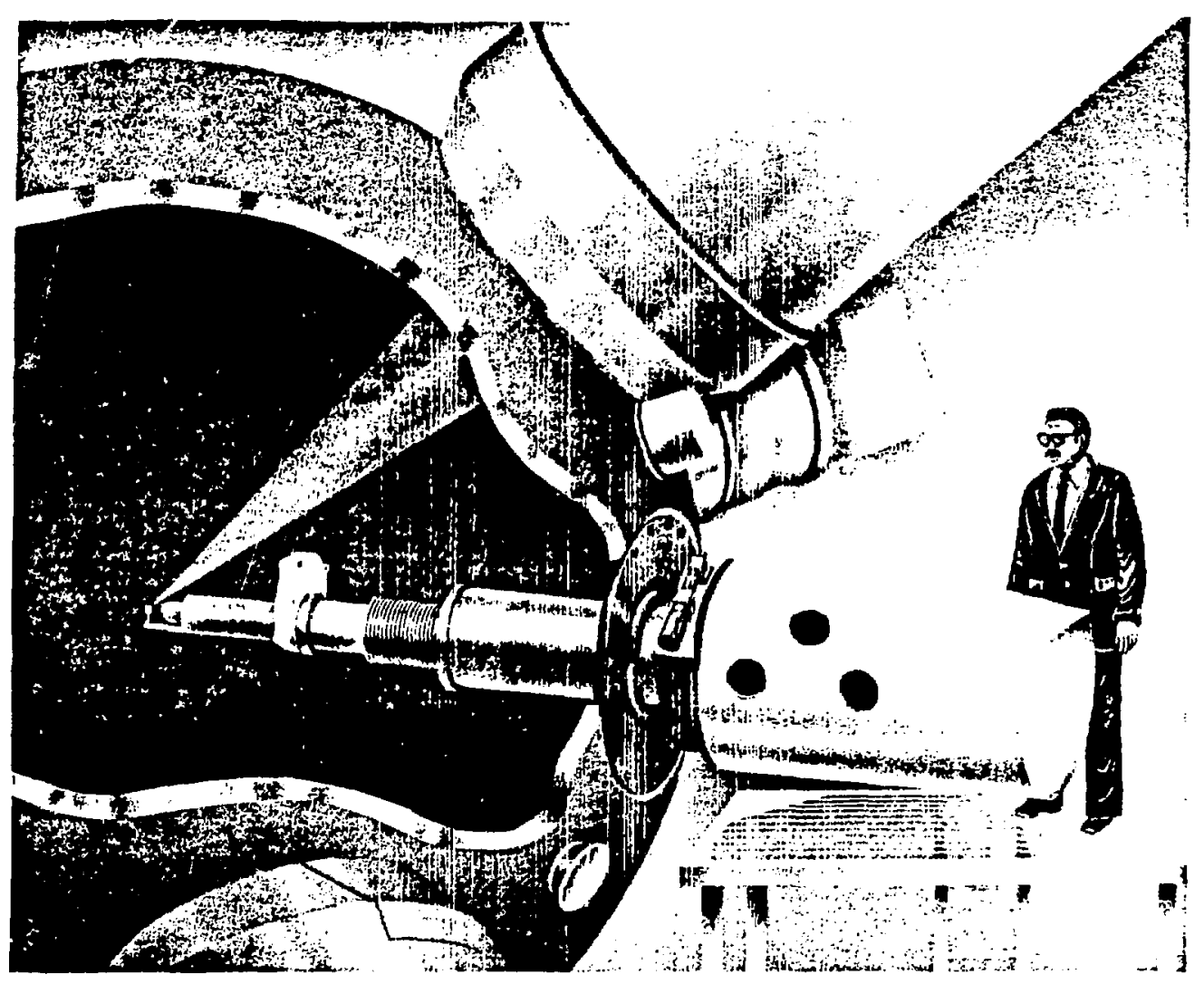

Figure 1. Nova target plane imager.

D = $-M_{1} \times 10 \mathrm{mal}$.

For a front objective with focal length, $f_{1}$, the object and image distances are:

$$
s_{1}-f_{1}\left(1-\frac{1}{M_{1}}\right) \text { and } s_{1}^{\prime}-f_{1}\left(1-M_{1}\right) \text {. }
$$

The confugates of the one-to-one relay are equal to $s_{1}^{\prime}$ :

$$
s_{2}-s_{2}^{\prime}-s_{1}^{\prime}-f_{1}\left(1-M_{1}\right)
$$

The overall length of the periscope is given by:

$$
3000 \mathrm{~mm}=s_{1}+s_{1}^{\prime}+s_{2}+s_{2}^{\prime}-f_{1} \frac{\left(M_{1}-1\right)}{H_{1}}+3 f_{1}\left(1-M_{i}\right)=\frac{\left(M_{1}-1\right)}{M_{1}} f_{1}\left(1-3 M_{1}\right)
$$

The effective collecting f-number of the front objective is:

$$
f_{y}=\frac{s_{1}}{D}-\frac{f_{1}\left(1-\frac{1}{P_{1}}\right)}{D} \text {. }
$$

We have generated three equations Involving four unspectfled parameters: $D, M_{1}, f_{1}$, and $f$. Given a particular $f$ value, we can solve for the remaining parameters. 


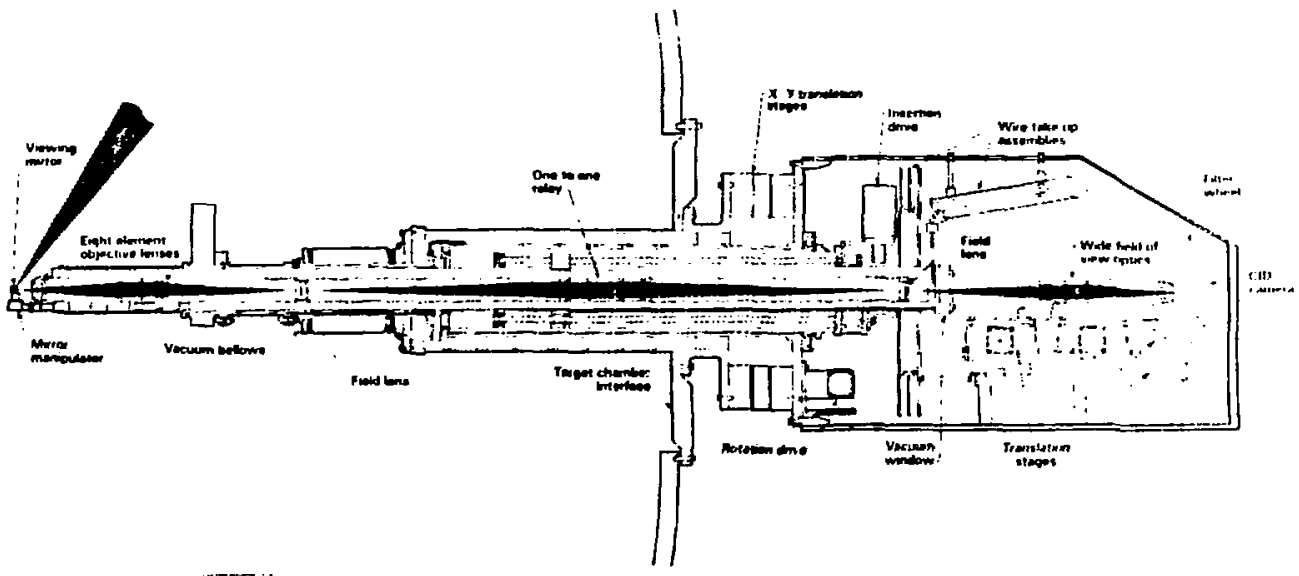

Figure 2. Nove target plene tmager asembly drawing.

Equations (1) and (3) combine to give an expression for $f_{1}$ :

$f_{1}=\frac{10 M_{1}^{2} f_{\#}}{\left(H_{1}-1\right)}$.

Substituting (4) Into (3) ylelds:

$$
\begin{aligned}
& 3 M_{1}^{2}-M_{1}-\frac{300}{f_{t}} \quad \text { or, } \\
& M_{1}=\frac{1-\sqrt{1+\frac{3600}{E_{1}}}}{6}=\frac{-10}{\sqrt{\mathrm{f}_{\emptyset}}} .
\end{aligned}
$$

Therefore:

$D=-M_{1} \times 10 \mathrm{~mm}=\frac{100 \mathrm{~mm}}{\sqrt{\mathrm{f}}}$.

Table 1 lists actual system values for geveral values of the collection f-number.

\begin{tabular}{|c|c|c|c|c|c|}
\hline$f_{z}$ & $M_{1}$ & $\stackrel{D}{(\mathrm{~mm})}$ & $\left.\underset{(\mathrm{m} i}{f_{1}}\right)$ & $\begin{array}{l}\text { First Relay } \\
\text { Length } \\
\text { (me) }\end{array}$ & $\begin{array}{c}\text { Second Relay } \\
\text { Length } \\
\text { (mol) }\end{array}$ \\
\hline $\begin{array}{l}2 \\
3 \\
4\end{array}$ & $\begin{array}{l}-6.9 \\
-5.6 \\
-4.8\end{array}$ & $\begin{array}{l}69 \\
56 \\
48\end{array}$ & $\begin{array}{l}121 \\
143 \\
160\end{array}$ & $\begin{array}{l}1092 \\
1112 \\
1130\end{array}$ & $\begin{array}{l}1908 \\
1888 \\
1870\end{array}$ \\
\hline
\end{tabular}

Table 1 .

Therefore, an $\mathrm{f} / 3$ collecting system can casily be contalned within a tube diameter of about $60 \mathrm{~mm}$.

\section{Achromatic vs. uncorrected chromatic}

Although the periscope must operate at $\lambda=0.351 \mu \mathrm{m}, 0.527 \mu \mathrm{m}$, and $1.054 \mathrm{\mu m}$, there is no requirement for simultaneous imaging at all these wavelengths. This 1s fortunate, since an achromatic $f / 3$ front objective would be quite ccaplex. In order to ensure high optical throughput at $3 \omega$, the front objective was designediusing only fused sjlfca. The objective 1 a nearly diffraction-IImited at all wavelengths, aithough the focal leagth 
changes slightly. A slight change in front conjugate, obtained by moving the entire periscope assembly, compensates for the shorter focal length at 0.351 w.

The 1:1 relay, approxtuately $1900 \mathrm{gm}$ long, is about $110 \mathrm{~mm}$ shorter at 0.35 um than at $1.05 \mathrm{\mu m}$ if it is made entirely of fused siljca. Since it is mechanicaliy inconventent to compengate for this large change, this relav is an achromatfc iens with equal length at $0.35 \mathrm{um}$ and $1.05 \mathrm{um}$. The smali field angle $\left(+2^{\circ}\right.$ ) and iow $f-n u m b e r$ ( $f / 16$ tn and out) permits the design to be implemented as back-to-back widely ajr-spacen telescope doublets. The Schott LFS filint elements ahgorb lesg then $5 \%$ of the energy et 0.35 wa.

The two fleld lenses are also achromatic doublets so that the pupł is properly relayed through the system in the wide field-of-view morle.

Netalls of the optical design are Included In FIgs. 3 and 4 and Table 2.

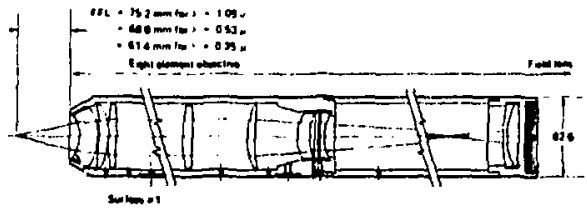

Table 2, Optical Design Parameters

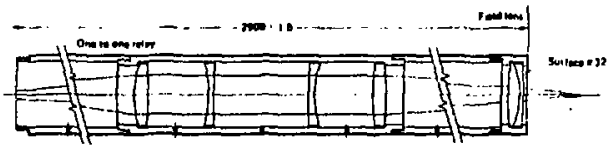

\begin{tabular}{|c|c|c|c|c|}
\hline Lens & Elmont & $\begin{array}{l}\text { Rodius of } \\
\text { cusveluet }\end{array}$ & mictomss & metertat \\
\hline $\begin{array}{l}\text { Elont clament } \\
\text { Dojective }\end{array}$ & $\begin{array}{l}1 \\
2 \\
3 \\
4 \\
3 \\
6 \\
6\end{array}$ & 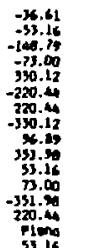 & 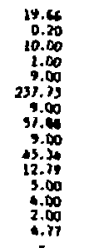 & 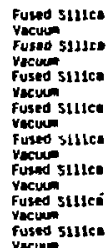 \\
\hline F1old Len: & 1 & $\begin{array}{r}223.76 \\
23.43 \\
52.53 \\
-223.78\end{array}$ & a,in & 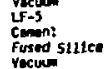 \\
\hline Ond to-ane & $\begin{array}{l}1 \\
2 \\
2 \\
1\end{array}$ & 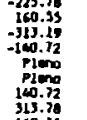 & $\begin{array}{l}14.73 \\
62.24 \\
6.03 \\
601.43 \\
6.43 \\
62.28 \\
12.72\end{array}$ & 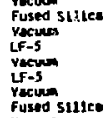 \\
\hline Fleve Lent & 2 & 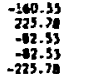 & 12.22 & 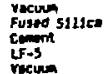 \\
\hline Mide rov & $\begin{array}{l}\text { nov } \\
? \\
2 \\
2 \\
1\end{array}$ & 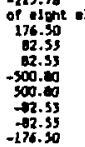 & $\begin{array}{l}\text { nt } \\
6.0 \\
0.01 \\
9.0 \\
9.35 \\
9.0 \\
0.01 \\
.0\end{array}$ & 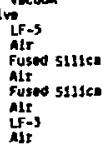 \\
\hline Merrou FOV & 1 & $\begin{array}{r}137.00 \\
40.40 \\
-119.50\end{array}$ & 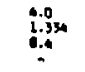 & $\begin{array}{l}\text { UF-s } \\
\text { Air } \\
\text { Fused sildee } \\
\text { M15 }\end{array}$ \\
\hline
\end{tabular}

Figure 3. Nova target plane Imager perficope optics.
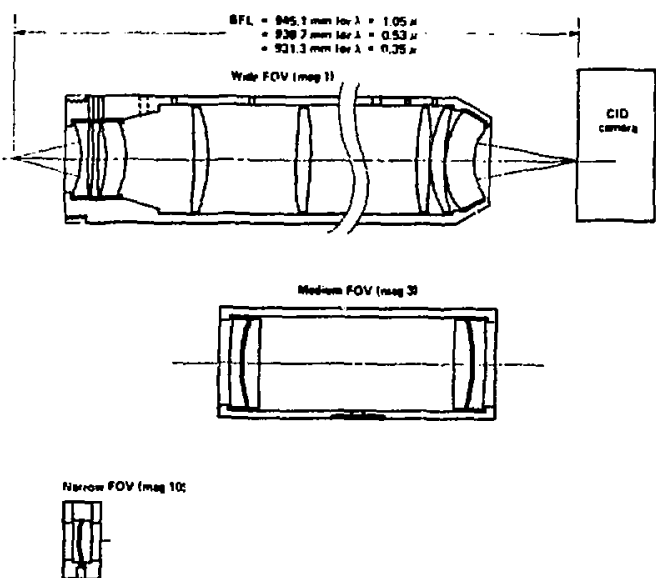

Eigure 4. Nova target plane Imager far-ffeld viewing optics. 


\section{Performance}

The Input to the target plane Imager was made fast (f/3) in order to achfeve high resolution and high sensitivity. In operation, the limiting factors on resolution are the graininess of the diffuse alignment retlcles used and the cID resolution. Eve: so, we have been able to resolve 7 un features and position focal spots to an accuracy of t15 $\mathrm{um}$. Although this could be Improved by using more sophiaticated Image analysia techniques, it has proven satis factory for our application.

System densitivity is determined by the signal-to-nolse ratio in the cIn cameras used, the solid angle of the instrument input, nnd the scattering characteristics of the reticles used. Since the target plane imager is effectively an $\mathrm{f} / 3$ system, the input solid angle is about $8.5 \times 10^{-2}$ steradians. Lsboratory measurements have deteral ned that the minimum detectable signal (signal-to-nolse ratio of 1 ) for the cip camera used $1 \mathrm{~s} 2 \times 10^{-7} \mathrm{~W} / \mathrm{cm}^{2}$ at $1.05 \mathrm{\mu m}, 1 \times 10^{-7} \mathrm{w} / \mathrm{cm}^{2}$ at $0.53 \mathrm{\mu m}$, and $1 \times 10^{-5} \mathrm{w} / \mathrm{cm}^{2}$ at $0.35 \mathrm{\mu m}$ (on the chip). Scattering characteristics of the reticle materlal have been measured also. When beam 18 incident on the frosted glass at an angle of $45 \%, 35-40 \%$ of the light is scattered forward into angles less than $15^{\circ}$. Abuut $50 \%$ of the $11 \mathrm{ght}$ is scattered forward into a lobe pattern that can be approximated by:
$R(\theta)=\frac{7 P s}{2 \pi}$
$\cos ^{6}$

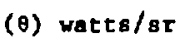

where Ps 1s about 50\% of. the Insident power. In addition, 10-15\% of the light 1s scattered into a similar patteri centered on the direction expected for specular reflection. The result 1s that the target plane Imager can view and align focused beang with a poyer of about $10^{-8}$ wate Incident at chamber center for 1.05 um and 0.53 um and about $10^{-6}$ watts at $0.35 \mathrm{um}$.

\section{Systen operntion}

Alignment of the 1 aser beams and the fuston target prtor to an experfment is accomplished using several interdependent subsystems at the target chamber. 2 Figure 5 includes these in block hlagram form. There are three target alfgnant viewers that determine an orthogonal reference frame in which target positions are measured. A typical alignment procedure involves positioning a reference reticle near chamber center using the alignment ald positioner. The precfse reticle location depends on tetails of the target. Next, the laser beams of the correct wavelength are focused onto the reference reticle as determined by the target plane Imager. Finally, the reference reticle $1 \mathrm{~s}$ removed and a fusion target $1 \mathrm{~s}$ precjsely aligned to chamber center using the target positioner. At this polnt all the vlewfng instruments are commanded to safe configuration before the target is irradiated.

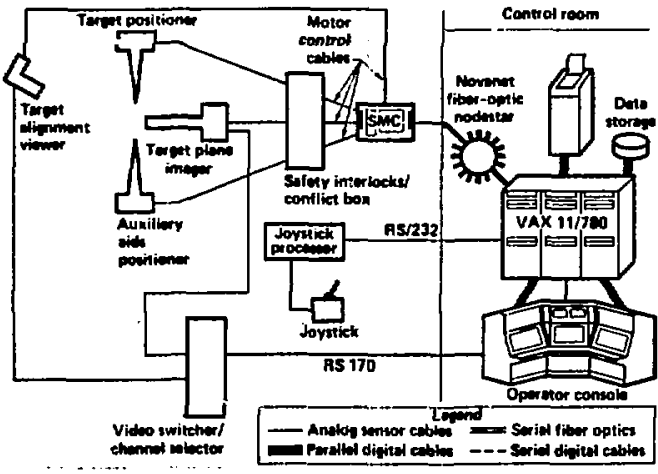

Figure 5. Nova manual target alignment controls.

\section{Computer controls of Nova target positioning devices}

The control system for target positiening devices is resident on two computers:

1. an LSI-11/23 alcrocomputer stepper motor controller (SHC); and

2. DEC VAX-11/780 which Is used to run operator interface software. 
The operator remotely comanis the tarpet fositioning devices through a series of touch screen menus displayed on a touch sensitive graphics video display (Fig. 6). When the operator lssues a command by touching the corresponding menu button, the vax-based software reads a configuration file contafining a list of the devices and setpolnts to move to complete the operation. Each target positioning device can have ten defined setpoints. Each setpoint has a table of motor positions corresponding to it stored in the SMC. The commands are 1ssued to the SMC across the local area network and the status of the completion reported back to the operator by updating the color of the chosen button on the menu.
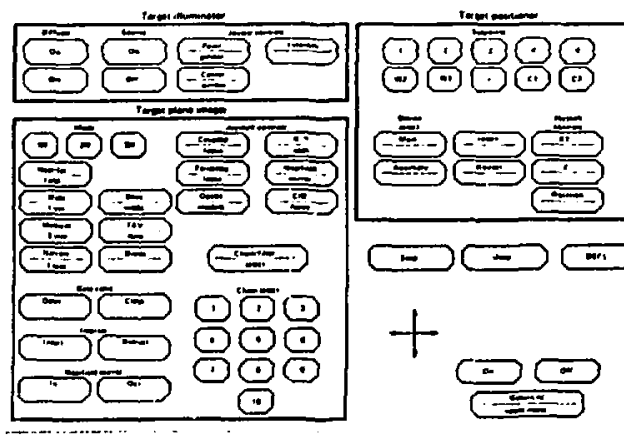

Figure 6. Nova target chamber alignment touch panel.

Having these compands file-based Instead of coded into the operator interface software eliminates the need to recomplle when change occurs in a positioning sequence. The operator would simply edit an ASCII file containing English-ilke commands which will then be used as the new configuration file during subsequent command operations. The configuration file schema allowed us to develope complex motions on multiple devices without a lengthy software development effort.

The VAX-based software also provides manual control for dynamic alignment functions such as final target positioning. A joystick is used to enter direction and rate sivultaneously for fine resolution slewing of device motors in two axes. The joystick has finer resolution at the slower slewing rates to make small adjustments easjer. Cross-coupling of motor coordinates is provided such that the observed image motion tracks the joyotick motion. Aiter the operator completes an adjustment to a target alignment device, he may then declare this new position as a setpoint. The new motor positions are updated in the SMC setpoint cable, which provides the operator with the flexibility to move from this position and return with a single command.

The SHC design is based on the alignment device, a collection of atepper motors that are related in alignment function. The SMC provides a local control panel with switches and programable alphanumeric displays which reflect the changeable function of each switch.

The sbllity to command groups of motors as a single device allows the operator to customize both local control panel and remote commands. A reservation system has been Implemented to prevent conflicts that result from two or more operatora trying to use the same device for dissimilar tasks at the same time. In addition to the software reservation gystem, the target alignment devices are hardware fnterlocked overriding any command sent which has the potential to cause a collision. The tncerlock systen uses contact switches on the alignment devices to sense position and matches these positions with a ROM atored truth table. If the interlock system detects a potential collision, it immediately cuts the power to the motor in the direction causing the conflict. The operator would then have to "back out" the device to correct the confilct situation.

\section{Conclusions}

During the past year, we have been using a target plane imager system to align the Nova laser beams. Operating at the focal point of the entlre laser gystem, it has access to most of the alignment information present. Therefore, it has proven to be one of the syatem's most valuable optical 1nstruments. Its nost foportant use is the routine alignment of harmonic beams prior to target shots. 


\section{Acknowledyments}

The authors wish to acknowledge the many contributions made by Noreen Connolly, Stefan Trenev, and Henry Atfles to the desfgn of this instrument. Furthermore, we wish to thank Rodney Saunders, James Wintemute, and James Hockett for their essential contributions during the construction and integracion phases of this system.

\section{References}

1. W. W. Almmons, R. D. Godwin, Nova Laser Fusion Facility: Design, Engineerfng and Assembly overview, Lawrence Livermore National laboratory, Livernore, CaIff., UCRL-88700 $(1983)$

2. C. D. Swift, E. S. Bliss, W. A. Jones, L. G. Seppala, "Three Wavelength Optical Alignment on the Nova Laser," In Proc. SPIE, May 1984 , vol. 483, p. 10.

3. P. J. VanArsdall, J. E. Krammen, J. A. Suart, R. G. Ozarsk1, J. R. Severyn, A. J. De Groot, Distributed Computer Control System in the Nova Laser Fusion Test Fac1lity,

Lawrence LTVermore National Laboratiry, Livermore, Calff,, UCRL-50025-85-2 (1985).

\section{DISCLAIMER}

This report was prepared as an account of work sponsored by an agency of the Uniteo States Government. Neither the United States Government nor any agency thereof, nor any of their employees, makes any warranty, express or implicd, or assumes any legal liability or responsibility for the accuracy, completeness, or usefulness of any information, apparatus, product, or process disclosed, or represents that its use would not infringe privately owned rights. Reference herein to any specific commercial product, process, or service by trade name, trademark, manufacturer, or otherwise does not necessarily constitute or imply its endorsement, secommendition, or favering by the United States Government or any agency thereof. The views and opinions of authors expressed herein do not necessarily state or reflect those of the United States Government or any agency thereof. 